\title{
DE SURINAAMSE GESCHIEDENIS SOCIOLOGISCH BEHANDELD
}

DOOR

\author{
W. R. MENKMAN
}

Dit jaar verscheen bij Mart. Nijhoff te 's Gravenhage Samenleving in een Grensgebied - Een sociaal-historische studie van de maatschappij in Suriname. door Rud. van Lier.

De onlangs gepromoveerde schrijver is, anders dan wellicht uit den aanhef van zijn werk begrepen zou kunnen worden, een zoon des lands, zoals op het eind blijkt.

Het boek heeft de bedoeling de tegenwoordige sociale verschijnselen in Suriname te interpreteren aan de hand der geschiedenis. De vraag zou gesteld kunnen worden of voor zodanige interpretatie een zo uitvoerig historisch overzicht, als in dit 425 bladzijden tellende boek gegeven wordt, wel nodig was. Schrijver echter meent ,dat het niet wel mogelijk was een kort begrip op te stellen van de ontwikkeling der Surinaamse maatschappij, als inleiding tot de studie der tegenwoordige sociale verhoudingen, zonder zich vooraf ernstig in het verleden te verdiepen.

Van de huidige bevolking acht de Heer van Lier de groep der Creolen voor het ogenblik die ,,met de grootste problemen in de Surinaamse samenleving" en tevens die welke nog steeds den grootsten invloed heeft op het lot des lands. Aangezien in het algemeen het begin van den laatsten wereldoorlog de tijdgrens is welke de schrijver zich gesteld heeft, neemt hij zich voor in een latere studie te behandelen wat wij zouden willen noemen de emancipatie der Aziatische groepen van den nieuwsten tijd.

Schrijver typeert de Surinaamse maatschappij als een meervoudige en met de stelling dat Amerika het westelijke grensgebied is der Europese beschaving verantwoordt hij den titel van zijn werk.

In het eerste hoofdstuk wordt Suriname behandeld als volkplanting, wat blijkbaar volgens des schrijvers inzicht betekent Suriname in de zeventiende en achttiende eeuw. Dat het patent 
van 1662 aan Willoughby en Hide het volle eigendomsrecht zou verleend hebben van Suriname, is een bewering welke tot misverstand aanleiding zou kunnen geven. De,,patentees" verkregen geen andere of meerdere rechten dan alle andere ,Lords proprietors", t.w. een bezitsrecht, een leen, waaraan zekere verplichtingen kleefden. Eigendom dus in een bepaalden zin, wat wel genoemd is Westindisch eigendom. Een bestuursperiode der WestInd. Compagnie, tussen het Zeeuwse tijdperk en dat van de Sociëteit, is er nauwelijks geweest.

Dit zijn onbetekenende opmerkingen, doch hetgeen er verder gezegd wordt over plantages zou wellicht tot meer commentaar aanleiding kunnen geven, wanneer zekerheid bestond dat de schrijver het ook op Suriname van toepassing acht.

Thompson's definitie van het begrip ,,plantation" had allicht geen betrekking op de particuliere landbouwonderneming in de tropen: de Engelsen spraken van hun overzeese nederzettingen als van $\mathrm{Hs}$ Ms Colonies and Plantations.

Dat pogingen gedaan werden om met blanke arbeiders het land te bebouwen, slaat niet op Suriname. De oude patroons zochten kolonisten, Willoughby en de Staten van Zeeland eveneens. Wat er gezegd wordt aangaande de ontmoeting van twee economische werelden door de invoering van het instituut der (neger) slavernij in de nieuwe wereld, is moeilijk te volgen. De stameconomie der Westafrikaanse negers speelde op de Westindische plantages geen rol meer; de slaven hadden niets af te leren, maar moesten alles aanleren, zoals lastdieren afgericht worden tot het verrichten van hun arbeid.

Nog een kleine opmerking; de door Crijnssen veroverde Willougbyschans was geen stenen fort, doch een houten versterking.

De bevolkingscijfers welke in dit hoofdstuk voorkomen worden gelukkig onder voorbehoud gegeven. Zo geeft de schrijver voor 1863 een totale bevolking van 49.132, waarvan slaven 31.380 en een stadsbevolking van 19.347. Het Kol. Verslag evenwel geeft per 31 Dec. 1862 een totaal van 52. 963,waarvan 36.481 slaven en een stadsbevolking, zonder het garnizoen van fort Zeelandia, van 18.666. Intussen is het duidelijk dat de bevolking van Paramaribo procentsgewijs voortdurend toegenomen is; welke rol hierbij de neiging, in de rijke periode, gespeeld heeft der stadsbewoners om er zoveel mogelijk huisslaven op na te houden, valt moeilijk na te gaan.

Dat op het eind der achttiende eeuw de bevolking hoofdzakelijk bestond uit meesters en slaven - en een middenstand ge- 
heel ontbrak, kan niet zonder enig voorbehoud aanvaard worden. Elf jaar na het eind der eeuw werd een volkstelling gehouden en toen bleek dat er anderhalf maal zoveel vrije zwarten en vrije kleurlingen waren als blanken. De blanken zullen niet allen meesters geweest zijn, de gekleurde groep der vrijen voor een klein deel wèl; de grens tussen blank en gekleurd zal destijds wel reeds niet nauwkeurig te trekken geweest zijn en middenstand is ook maar een relatief begrip. Dit alles maakt de sociologische studie betreffende oude slavenkoloniën extra moeilijk.

Volgens hoofdstuk II (De Meesters) zou door de economische crisis van 1775 (welke zich overigens al eerder was begonnen af te tekenen) Suriname het karakter van volkplanting min of meer verloren hebben. Blijkbaar heeft schrijver gedacht aan het absenteïsme, dat echter ook vroeger wel bestaan had en waarvan het toch de vraag is of het de sociale structuur der samenleving wel sterk veranderde. Dit ook in verband met hetgeen gezegd wordt aangaande het gebrek aan Europese vrouwen en het in concubinaat leven van blanke mannen met niet-blanke vrouwen.

Op het gebied der religiositeit gaat het niet op Suriname, of welke andere Westindische volkplanting ook, te vergelijken met de Nieuwengelandse koloniën. Noch de Nederlanders noch de Engelsen waren om des geloofs wille naar de tropen uitgeweken.

Met betrekking tot den aanhef van hoofdstuk III, dat onze volkplanting als slavenkolonie behandelt, rijst de vraag welke andere koloniën, behalve de Guyanas en de Ned. Antillen, op een Calvinistisch moederland konden wijzen. En de slavernij hadden alle Amerikaanse koloniën met elkander gemeen, terwijl die slavernij in het tropische deel der nieuwe wereld overal vrijwel dezelfde trekken vertoonde.

Dat de slavernij ook op het karakter en de mentaliteit der blanke meesters een stempel drukte, is al herhaaldelijk opgemerkt. Men had aan den enen kant onbeperkte macht over zijn slaven, aan den anderen was men niet alleen voor zijn materiële welvaart van hun arbeid afhankelijk, maar men leerde ook van jongs af zich tot in kleinigheden te laten bedienen, wat een zekere hulpeloosheid schiep. Waar dan inderdaad nog bij kwam, dat men zich wel bewust moest zijn van het gevaar dat in de zeer onevenredige getalsverhouding school.

Het is echter de vraag of er in Suriname, naast de slaven-mentaliteit, ook van de meesters-mentaliteit nog iets van betekenis bij de tegenwoordige Surinaamse bevolking is blijven hangen. Op de Britse Westindische eilanden en in de zuidelijke staten der 
Unie zullen nog wel blanken leven wier onmiddellijke voorouders slaven hielden, maar in Suriname kan hiervan nauwelijks sprake zijn.

Wanneer wij lezen dat de verhouding tot de slaven ook op een zekere ideologie berustte en dat de machtspositie der meesters uitspattingen hunnerzijds, sadistische en andere, in de hand werkte, dan denken wij onwillekeurig terug aan de dagen der Duitse terreur, toen niet alleen de overweldigers ,maar helaas ook vele onzer landgenoten, zich tegenover weerloze medemensen op de afschuwelijkste wijze te buiten gingen. Dat, wanneer de omstandigheden er gunstig voor zijn en bij het individu de aanleg aanwezig is, ,,psychopatisering” plaats heeft, schijnt van alle tijden te zijn en ook niet gebonden aan ras, lokaliteit of klimaat.

De negers zelf, althans de pas uit Afrika aangevoerde, zullen wel uit zich zelf den blanke als een verheven wezen beschouwd hebben; de naam ,,bakra” schijnt hierop te wijzen.

Het achttiende eeuwse geval van een huwelijk tussen een vrije zwarte vrouw en een blanken man geeft ons niet alleen een kijk op de inzichten der Surinaamse autoriteiten, maar ook op die der moederlandse, die zich eenvoudig op het standpunt stelden dat zodanig huwelijk niet met enige wettelijke bepaling in strijd was.

Schizoïde trekken vertonen ook onze tegenwoordige oorlogsmisdadigers bij de vleet.

Dat er grote sexuële vrijheid onder de slaven heerste zal wel in overeenstemming geweest zijn met de zeden in het Afrikaanse stamland. Het geringe geboortecijfer onder de slaven is ook wel toegeschreven (Darwin) aan de omstandigheld dat ook de mens, evenals sommige dieren in gevangenschap, zich in de onvrijheid niet voortplant, een psychisch verschijnsel dus; er zullen echter ook wel andere oorzaken geweest zijn.

Het huishoudster-systeem, oftewel Surinaams huwelijk, zoals de schrijver het ons schetst, is nog lang in ere gebleven; eerst Gouverneur Idenburg heeft er, voor zover het mannen in overheidsdienst betrof, een einde aan trachten te maken. De op deze wijze levende Europeanen in Suriname zullen thans wel uitgestorven zijn; een enkele keer werd hun samenleving met een vrouw des lands op het einde door een huwelijk besloten, ter wille van het eventuële weduwpensioen. Erkenningen, ook zonder huwelijk, door de Europese vaders, kwamen eveneens voor.

Intussen is heden ten dage, een grote mensenleeftijd na de emancipatie, onder de bevolkingsgroep welke statistisch die der 
inboorlingen heet, maar zonder de Bosnegers en de Indianen en ook de Aziatische groepen buiten beschouwing gelaten, het aantal illegitieme geboorten nog steeds groot.

Ten slotte, dat ook buiten de laagste Surinaamse volksklasse, het geloof in Afrikaanse (of Indiaanse) geneeswijzen bestaan gebleven is, lijkt niet vreemd. Europese wonderdokters hebben zich nu eenmaal niet in Suriname gevestigd en in bepaalde gevallen wenden ook ontwikkelde personen zich in arren moede vaak tot kwakzalvers.

Wat er over de joodse bevolking gezegd wordt (hoofdstuk IV) geeft geen aanleiding tot veel commentaar. Alleen zou men kunnen vragen of het de bedoeling was te zeggen, dat al in den beginne de andere kolonisten uit het vaderland een latent antisemietisme medebrachten. Ziet dat wellicht hierop, dat Van Sommelsdijck, aan zijn lofrede op ,den Heer” Samuel Nassy toevoegde: „Jodenschap apart"?

Ook op het midden der achttiende eeuw waren er in Suriname Joden en Joden. Joachim Nettelbeck vertelt dat aan boord van zijn schip een kleine joodse koopman onder toezicht van den fiscaal door enige matrozen afgeranseld werd, omdat hij een frauduleuze klacht tegen den kapitein ingediend zou hebben. In dezelfde „Lebensbeschreibung” lezen wij dat in 1759 de eigenaar der plantage De Maasstroom, een gewezen soldaat uit Wenen en blijkbaar een Jood, toen hij naar Europa afreisde, blijkens een afscheidsovatie zijner 400 slaven, voor dezen een goed meester geweest moet zijn.

Hoofdstuk V is gewijd aan de vrije kleurlingen en vrije negers en aan de positie der gemanumitteerden. Ook hier staan wij, wat de getalsterkte betreft, voor het feit dat de oude cijfers wel niet betrouwbaar geweest zullen zijn. Laat in de achttiende eeuw zullen in Suriname, evenals elders, wel ongemerkt kleurlingen in de klasse der blanken overgegaan zijn. De Moniteur des Indes Oriëntales et Occidentales 1846-1847 zegt: . . . les enfants obtiennent enfin le nom de créoles blancs".

De cijfers der manumissies, door den schrijver gegeven voor de periode 1857-1862, geven natuurlijk meer houvast. Welke verschillende motieven bij de meesters golden om hun slaven of slavinnen vrij te laten, valt thans moeilijk meer te beoordelen; het is echter inderdaad merkwaardig, dat het aantal manumissies sterk toenam, nadat in 1850 de beperkende bepalingen ingetrokken waren. Een pijnlijke misstand moet het altijd geweest zijn, dat een vader zijn bij een slavin verwekte kinderen niet kon 
vrijkopen, wanneer een ander eigenaar was der moeder en zijn toestemming weigerde, of te hoge eisen stelde.

Dat in de achttiende eeuw vrijgeboren negers, die enig onroerend goed bezaten en tot een kerkgenootschap behoorden, aan de verkiezingen konden deelnemen, was zeker, als staaltje van liberale politiek, de vermelding waard; men vergelijke daarmede den tegenwoordigen toestand in sommige delen der V.S.

De opgaven der joodse kleurlingen zou nog aangevuld kunnen worden met de opgave van Teenstra, die hun aantal in 1830 stelt op 50, waarvan 1 zwart.

Wat betreft de armoede onder de ,,vrijlieden”, tot kort voor de emancipatie, werd in het Surinaamsch Weekblad van 23 Sept. 1860 als een der oorzaken genoemd de betrekkelijke overproductie van bepaalde voedingsmiddelen, door hen bij voorkeur verbouwd.

Het aan de kleurlingen gewijde hoofdstuk is wel daarom zo interessant, omdat hun groep, ook wel die der Creolen genoemd, thans in bepaalde opzichten de belangrijkste is der Surinaamse bevolking.

Het hoofdstuk over de slaven neemt 63 bladzijden in beslag. Inderdaad is de negerslavernij een belangrijke factor geweest in de geschiedenis van Suriname; zij drukte zolang zij bestond een stempel op de samenleving, in Suriname zowel als elders. Voor zover dit stempel nog niet uitgewist zou zijn, speelt dan de vroegere staat van dienstbaarheid van het voorgeslacht de grootste rol, dan wel de Afrikaanse invloed? Het lijkt moeilijk uit te maken.

Wat de geschiedenis van den slavenhandel betreft, zijn het zeker niet de inboorlingen geweest, die de Portugezen van de westkust van Afrika verdreven, zoals de schrijver schijnt te menen.

Beschouwingen over de afkomst der slaven en het aangevoerde aantal in den loop der tijden, zijn inderdaad nogal speculatief. Hetzelfde kan gelden voor de behandeling welke zij in Suriname in den regel ondervonden; de schrijver neemt dan ook wat dit punt betreft een zoveel mogelijk objectief standpunt in. Misschien zal men later dezelfde voorzichtigheid betrachten bij de beoordeling van het tegenwoordige systeem van dwangarbeid in Rusland.

Terecht wijst de schrijver er op, in verband met de slechte reputatie van Suriname ten aanzien van de behandeling der slaven, dat vertegenwoordigers van naijverige vreemde naties niet de meest betrouwbare getuigen zijn. Verder, dat in criminele gevallen ook op vrijen nog lang barbaarse straffen toegepast zijn en dat in het militaire strafrecht pas onder Koning Willem III de 
lijstraffen afgeschaft zijn; niet vergeten mag worden dat het plantagepersoneel in Suriname veelal uit oud-militairen bestond, die aan een ruwe behandeling gewend waren. Art. 43 van het regeringsreglement van 1828 sprak van straffen van meer dan honderd slagen voor slaven die zich aan criminele delicten schuldig gemaakt hadden. En in dienzelfden tijd werd officiëel een tarief vastgesteld voor het appliceren van den Spaansen Bok. Deze gruwelijke strafoefening, welke voor het eerst in het begin der zeventiende eeuw in Brazilië waargenomen werd, konden nog lang daarna in Suriname de meesters, tegen betaling, in het fort door militairen op hun slaven laten toepassen.

Harde tuchtiging der kinderen van de lagere volksklasse is een algemeen verschijnsel in de oude Westindische slavenkoloniën; in hoever dit inderdaad een staartje is van de slavernij is ook al weder moeilijk te zeggen. De schrijver doet het voorkomen alsof dit euvel in Suriname nog altijd voortbestaat; laten wij hopen dat hij zich daarin vergist. Een veertigtal jaren geleden ergerden Europeanen zich nogal eens aan hetgeen zij dienaangaande op de erven achter hun woningen waarnamen en destijds kwam het ook nog voor dat ouders hun opgroeiende kinderen die zij zelf niet meer baas konden worden, bij de Politie brachten ter afstraffing; dit zal nu toch zeker wel tot het verleden behoren.

Dat vrije kleurlingen, of vrijverklaarden, die er zelf slaven op na hielden, strenge tuchtmeesters waren, is eveneens geen typisch Surinaams verschijnsel; het regelrechte verband met de slavernij zelf lijkt hier duidelijker.

Het exploitatiesysteem ging niet gepaard met een hooghouden van het prestige der meesters, in Suriname niet en elders ook niet. Het pleit voor de slaven dat zij hun ouden van dagen en gebrekkigen zelf onderhielden, doch het had de taak der eigenaars behoren te zijn. Sexueel verkeer met slavinnen en handeldrijven met slaven, alsmede het profiteren van de prostitutie der slavinnen, kon al evenmin strekken om den meester als een sujerieur wezen te doen zien. Dit alles echter waren ook alweer geen specifiek Surinaamse misstanden; er is ook een buitenlandse, meer in het bijzonder een Franse slavenlitteratuur, waarin de meesters van vreemde nationaliteit evenmin in een gunstig daglicht verschijnen. En in den slaventijd zelf wist men buiten de koloniën eigenlijk weinig van de toestanden af; de slaven vermoedden dit zelf ook wel, getuige het liedje dat zij zongen bij het bezoek van Prins Hendrik aan Suriname in 1835.

De gezinsband kon onder slaven uit den aard der zaak niet 
sterk zijn en terecht vermoedt de schrijver dat de gehechtheid aan den (plantage) grond eigenlijk meer was gehechtheid aan de mensengemeenschap waarin men op de plantage leefde. Het gezinsleven is in Suriname nog altijd onvoldoende ontwikkeld on-, der de volksklasse; van bijzondere gehechtheid aan het land, zoals in de zuidelijke staten van Amerika, is hier niet zoveel te bespeuren. Dat de slaven zich zo vaak vrouwen zochten op andere plantages dan die waaraan zij zelf verbonden waren, wees misschien op een oude Afrikaanse zede, het hebben van een vrouw in een ander dorp, thans ook nog bij de bosnegers in zwang.

Hoe armelijk het bestaan van den slaaf ook in den regel was, dat hij soms aan geld wist te komen om goeden sier te maken, ook dit is een verschijnsel dat elders eveneens waargenomen werd. Er bestond in dit opzicht natuurlijk een groot verschil tussen de stads- en de plantageslaven.

Het zou wel interessant geweest zijn eens te onderzoeken wat de Afrikanen in Suriname meer speciaal van hun joodse meesters overgenomen hebben, op het punt van taal en gebruiken; wellicht ook omgekeerd. Is ,,treef” typisch Afrikaans, of heeft het met de joodse spijswetten te maken?

Aardeten en slaapziekte worden door Teenstra genoemd als onder de negerslaven voorkomend; Van Lier spreekt hier echter niet over.

Dat Afrikaanse afgoderij, als ook onderlinge vrees voor vergiftiging of zwarte kunst, onder de lagere volksklasse zijn blijven voortleven, is bekend, niet als een specifiek Surinaams, maar als een algemeen Westindisch verschijnsel.

Wat wij lezen over het aantal Christenen onder de slaven is niet duidelijk, of niet volledig. Volgens het rapport der Staatscommissie waren in 1851 van de 38.545 slaven 125 Hervormd, 16 Luthers, 6010 R.K. en behoorden 17.574 tot de Mor. Broedergemeente, zodat 14.820 als heidenen beschouwd moesten worden.

Ook wat de getalsverhouding tussen mannen en vrouwen betreft geeft het bovengenoemde rapport cijfers welke niet kloppen met hetgeen Van Lier zegt. Een sterktestaat der slaven wijst voor de periode 1844-1854 een voortdurend overschot van vrouwen aan. Het kan natuurlijk zijn dat er speciaal op de plantages te weinig vrouwen waren, maar dat zou dan toch spoedig anders geworden zijn. Volgens het Kol. Versl. immers waren er op 31 Dec. 1862 niet alleen in Paramaribo, maar ook in alle districten meer vrouwen dan mannen; de leeftijden echter worden niet gegeven.

Wat ten slotte het vervoer met de slavenschepen betreft zijn 
er nog andere autoriteiten dan Gallandat. Deze anatomiae, chirurgiae et artis obstertieanti lector te Vlissingen, die zelf als opperheelmeester op slavenschepen gevaren had, zag in den slavenhandel geen kwaad en ook niets onchristelijks. Het was inderdaad moeilijk een slavenlading zonder al te veel sterfgevallen en ziekten over den oceaan te brengen, doch in het algemeen slaagden de Nederlandse schippers in de achttiende eeuw daar nogal goed in; wantoestanden als bij Engelsen en Amerikanen kwamen bij ons niet voor. Men zie Nettelbeck's levensbeschrijving, ook door Van Lier geraadpleegd, als ook het boekje van J. Hudig Dzn. uit oude rederijpapieren samengesteld.

Het korte hoofdstuk VII, over de emancipatie en de periode van het zgn. staatstoezicht, is vooral belangrijk omdat het den veel besproken misstand, dat de slaven, eenmaal vrijverklaard, de plantages verlaten zouden hebben en naar de stad getrokken zouden zijn, tot de juiste afmeting terugbrengt.

Onder den titel Het regeringsbeleid en het karakter van de periode na 1863, geeft de schrijver o.a. economische en financiële beschouwingen. Dat de Surinaamse bevolking haar economische zelfstandigheid lang vóór de emancipatie verloren zou hebben, doet de vraag rijzen, in welk tijdvak die bevolking dan wèl economisch zelfstandig geweest zou zijn. En dat Suriname het karakter van een volkplanting verloren zou hebben toen de gewezen slaven vrije burgers werden, is een redenering welke getuigt van des schrijvers eigen opvatting betreffende het begrip volkplanting.

Verder treffen wij in dit hoofdstuk een goed overzicht aan van de tot omstreeks 1930 door de moederlandse regering gevoerde assimilatiepolitiek en de poging tot ,,verindisching" van Suriname, welke gezien mag worden in de daarop gevolgde koerswijziging.

Ook zonder nader onderzoek lijkt het niet waarschijnlijk dat Suriname, laat ons zeggen de laatste tachtig jaar, aan het Nederlandse volk belangrijk minder gekost zou hebben dan aan den Nederlandsen staat. De verhouding is veranderd sedert Van Sypesteyn in 1854 schreef dat Suriname, alles in aanmerking genomen, eigenlijk geen lastpost was.

De opbouwpolitiek van het moederland en de stromingen welke daarin te bespeuren geweest zijn, vinden wij in dit hoofdstuk goed beschreven.

Uit een artikel van deskundige zijde in den XXVIIen jaargang van De West-ind. Gids had de schrijver wellicht nog wel iets kun- 
nen putten betreffende den aard der ,rituële” of ,religieuze” gebruiken van Afrikaanse herkomst, welke in Suriname nog altijd onder de strafwet vallen.

In een zeer omvangrijk hoofdstuk (IX) worden behandeld de economische en sociale veranderingen na de emancipatie.

Allereerst wordt de aandacht gevestigd op het behoud van het agrarisch karakter van Suriname, met geleidelijke verschuiving echter van de plantage naar het zelfstandige kleine landbouwbedrijf, als belangrijkste factor. De geschiedenis der vestigingsplaatsen en van den creoolsen landbouwer, ook als producent van een export artikel als cacao, wordt ons beschreven, alsmede de ontwikkeling van den rijstbouw, welke vooral op rekening van den Aziatischen kolonist gesteld moet worden. Het is hier dat ook een enkel woord gewijd wordt aan de zgn. ,Hollandse boeren”

Ook vinden wij hier nog eens een bestrijding der mythe dat de geëmancipeerde direct de plantage verlaten en de Creool den landbouw den rug toegekeerd zou hebben.

Bijzondere aandacht wordt geschonken aan de bewoners van het district Coronie en aan de zgn. Paranegers. Ook de aanvangs-geschiedenis der Aziatische immigranten wordt besproken, als mede de positie van den Creool in het bos- en mijnbedrijf, de werkloosheid en de uittocht van Surinamers naar de Nederlandse Antillen.

Op sociaal gebied vinden wij de raskwestie behandeld en de tegenstelling Surinamer-Hollander, met citaten uit de geschriften van leden der beide groepen. Wat dit laatste betreft moet altijd in het oog gehouden worden, dat gebrek aan waardering over en weer wel eens gepaard ging met onvoldoende bekendheid der ene groep met de andere. Ook aan de positie der Joden in Suriname wordt in dit hoofdstuk wederom aandacht besteed.

Verder worden behandeld de sexuële verhoudingen, ook de abnormale onder vrouwen, het huwelijk, het concubinaat en de buitenechtelijke geboorten; op het vraagstuk der prostitutie wordt niet uitvoerig ingegaan.

Eindelijk onderwijs, hygiëne, woningtoestand, godsdienstig leven en primitieve (Afrikaanse) religieuze gebruiken. Enige staatjes geven overzichten van geboorten- en sterftecijfers.

Het Xde hoofdstuk, handelende over het staatsbestel en de politieke spanningen, is het omvangrijkste deel van het boek. Na de achttiende eeuwse voorgeschiedenis worden de verschillende regeringsreglementen en de staatsregeling aan beschouwingen onderworpen; dat Suriname ook na 1863 nog altijd een volkplanting gebleven zou zijn wordt opnieuw een fictie genoemd. 
Bij de toepassing der regelingsbevoegdheid van het moederland vóór en na 1901, al dan niet met medewerking van den landvoogd, wordt uitvoerig stilgestaan. Wie dit alles leest komt opnieuw tot de overtuiging ,dat het wel zeer te betreuren was dat Nederland zich niet bepaald heeft tot het uitoefenen van het vetorecht, ten einde wat tegen het rijks- of het landsbelang geacht werd tegen te houden, maar ook wel de regelingsbevoegdheid positief uitgeoefend heeft, aan Suriname heeft opgedrongen wat het vertegenwoordigend lichaam, soms op goede gronden, niet wenste. Er is hierdoor onnodig kwaad bloed gezet.

Ook lezen wij in dit laatste hoofdstuk het een en ander over de benoemings-kwestie, een teer punt in Suriname, alsmede over de „,verindisching”, vooral onder het bewind van Gouverneur Kielstra, wiens beleid tegenover de Staten veroordeeld wordt. Verder wordt ons verteld hoe het vertegenwoordigend college gaandeweg een oppositie-orgaan werd, in plaats van een met het bestuur samenwerkend.

De geschiedenis der ontwikkeling van het politieke bewustzijn der bevolking gaat tot de recente invoering van het algemeen kiesrecht, omvat dus de periode der oude kiesverenigingen.

Interessant is ten slotte het verhaal der gebeurtenissen van 1891, 1911, 1931 en 1933; die van 1947 viel blijkbaar buiten het kader. Wat gezegd wordt aangaande een latente vijandigheid in de volksklasse (tegen het gezag als zodanig) heeft natuurlijk geen betrekking op een specifiek Surinaams verschijnsel.

De schrijver vergelijkt, wat het gedrag der massa betreft, het oproer van 1891 met de wanordelijkheden van 1931 en 1933. Trekt men een parallel tussen het Killingercomplot en het Urbina-dito, wat ook wel mogelijk lijkt, dan komt het Surinaamse bestuur van 1911 er heel wat beter af, op het punt van waakzaamheid en juist beleid, dan het Curaçaose van 1929.

Nog een vergelijking wordt ten slotte door den schrijver gemaakt, op het gebied der massapsychologie, t.w. tussen de Britse Westindische koloniën en Suriname. In het algemeen schijnt men wel te kunnen zeggen, dat uitbarstingen van agressiviteit in het Britse gebied veelvuldiger en ernstiger geweest zijn dan in het Nederlandse.

In zijn slotwoord verklaart de schrijver, waar hij misstanden heeft moeten signaleren, niet de bedoeling gehad te hebben oud zeer opnieuw te doen schrijnen. Hij wilde begrip wekken in Nederland voor de Surinaamse samenleving, zijn doel was niet te verdelen, doch te verbinden. 
Het boek eindigt met een omvangrijke bibliographie, 26 bladzijden genummerde aantekeningen en een index.

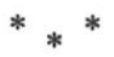

Aanvankelijk is men geneigd Dr Van Lier's werk te beschouwen als een geschiedenisboek, in een wat anderen vorm dan de gebruikelijke chronologische. Heeft men echter het geheel aandachtig gelezen, dan komt men tot de slotsom dat wij hier te doen hebben met een geschiedenis van Suriname, waarin zoveel mogelijk het accent gelegd is op het sociale. Op andere wijze was ook inderdaad het doel van den schrijver, de Surinaamse samenleving te schetsen, moeilijk te bereiken. Tegenwoordige toestanden en verhoudingen tot uitgangspunt nemend - en die waar nodig en mogelijk te verklaren uit de geschiedenis, zou afstuiten op het bezwaar dat die geschiedenis bij het grote publiek te weinig bekend is.

Dit in aanmerking genomen moet deze studie als verantwoord beschouwd worden - en een belangrijke bijdrage geacht worden tot de kennis van Suriname.

Aug. 1949 